\title{
13. DNA Recognition Rules for Steroid Hormone Receptors and GATA1 (2): Specificity of the Rules
}

\author{
By Masashi SuZUKI*),†) and Naoto YAGI**)
}

(Communicated by Setsuro EbaSHI, M. J. A., May 12, 1994)

\begin{abstract}
The DNA recognition rules for transcription factors of the $\mathrm{C} 4$ class described in the preceeding paper are further examined. By designing a computer program we show that the rules are specific enough to predict binding sites in the regulatory sequences of DNA.
\end{abstract}

Key words: DNA recognition; transcription factor.

1. Introduction. In the preceding paper ${ }^{1)}$ we have shown that a set of rules can consistently explain the contacts to DNA bases from amino acid residues in recognition helices of the $\mathrm{C} 4$ class of transcription factor. However, this does not mean that these rules are sufficiently specific to explain how a 4 factor finds its binding site on DNA-i.e. if there are many DNA sequences to which contacts can be made from the same recognition helix in similar ways, the rules cannot distinguish the proper site from the other complying DNA sequences. A particular DNA sequence must look "preferable" to the factor, or in other words the recognition rules must be specific enough to exclude the other DNA sequences.

2. Binding specificity. To examine the specificity of the rules we have designed a computer program which calculates a score for evaluating the match between the given protein and DNA sequences according to the chemical and stereochemical rules. ${ }^{1}$ This score loosely reflects the binding energy and is calculated as the sum of [stereochemical score (Fig. 1b)] $\times$ [chemical score (Fig. 1a)]. Firstly the program identifies possible amino acid and base positions for contact following Fig. $1 \mathrm{~b}$ and gives 10 points if the amino acid residue is one of the right sizes, and zero point if it does not. Then it multiplies the stereochemical score by the chemical score, following Fig. 1a, depending on the particular residue and base found at the positions. By summing up such figures for all the possible combinations of amino acid and DNA base positions the binding score is calculated.

By trying all possible DNA sequences of four bases-i.e. by examining all the $4^{4}=256$ sequences and by calculating the score for each DNA sequence with a fixed protein sequence, the score given to the real binding site is compared with those given to the rest (Figs. 2a-c). The real binding site is found among a few sequences for which the highest score is given, and these highest scoring sequences are distinguished from the remaining 97-98\% (see Fig. 2).

Another way of examining the specificity of the rules is to examine the regulatory DNA region by calculating a score along it-i.e. to determine the binding site of the factor by the rules and compare it with that identified experimentally (Fig. 3a). A regulatory element of DNA, the mouse mammary tumour virus long terminal repeat (MMTV-LTR), is bound by a number of glucocorticoid receptor molecules. ${ }^{2)}$ It has been shown by

*) MRC Laboratory of Molecular Biology, Hills Road, Cambridge, CB2 2QH, U.K.

**) Department of Pharmacology, Tohoku University School of Medicine, Seiryo-machi, Aoba-ku, Sendai 980-77, Japan.

†) Correspondence to: M. Suzuki. 
a

\begin{tabular}{|c|c|c|c|}
\hline $\mathrm{AA}$ & BASE & SCORE & SIZE \\
\hline Ala & $\mathrm{T}$ & 10 & $\mathrm{~s}$ \\
\hline Val & C & 8 & $\mathrm{~s}$ \\
\hline Val & $\mathrm{T}$ & 12 & $\mathrm{~m}$ \\
\hline Ile & $\mathrm{C}$ & 8 & $\mathrm{~m}$ \\
\hline Ile & $\mathrm{T}$ & 12 & $\mathrm{~m}$ \\
\hline Leu & $\mathrm{C}$ & 8 & 1 \\
\hline Leu & $\mathrm{T}$ & 12 & 1 \\
\hline Met & $\mathrm{C}$ & 8 & 1 \\
\hline Met & $\mathrm{T}$ & 12 & 1 \\
\hline Met & A & 5 & l \\
\hline Tyr & $\mathrm{T}$ & 12 & $\mathrm{a}$ \\
\hline Tyr & $\mathrm{C}$ & 8 & $\mathrm{a}$ \\
\hline Tyr & $\mathrm{AG}$ & 5 & $\mathrm{a}$ \\
\hline Phe & $\mathrm{T}$ & 12 & a \\
\hline Phe & $\mathrm{C}$ & 8 & $\mathrm{a}$ \\
\hline $\operatorname{Trp}$ & C & 10 & a \\
\hline $\operatorname{Trp}$ & $\mathrm{T}$ & 10 & a \\
\hline $\operatorname{Trp}$ & A & 5 & $\mathrm{a}$ \\
\hline Ser & ATGC & 10 & $\mathrm{~s}$ \\
\hline Cys & ATGC & 10 & $\mathrm{~s}$ \\
\hline Thr & ATGC & 10 & $\mathrm{~s}$ \\
\hline Asn & A & 15 & $\mathrm{~m}$ \\
\hline Asn & TGC & 10 & $\mathrm{~m}$ \\
\hline Gln & A & 15 & 1 \\
\hline Gln & TGC & 10 & l \\
\hline Asp & $\mathrm{C}$ & 12 & $\mathrm{~m}$ \\
\hline Asp & A & 10 & $\mathrm{~m}$ \\
\hline Glu & $\mathrm{C}$ & 12 & 1 \\
\hline Glu & A & 8 & 1 \\
\hline His & G & 12 & $\mathrm{~m}$ \\
\hline $\mathrm{His}$ & ATC & 8 & $\mathrm{~m}$ \\
\hline Lys & G & 15 & 1 \\
\hline Lys & $\mathrm{T}$ & 5 & 1 \\
\hline Lys & A & 3 & l \\
\hline Arg & $\mathrm{G}$ & 15 & l \\
\hline Arg & $\mathrm{T}$ & 5 & l \\
\hline Arg & A & 3 & l \\
\hline
\end{tabular}

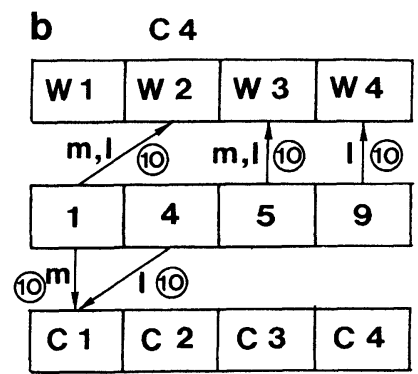

Fig. 1. Chemical (a) and stereochemical (b) scores for binding. In (b) the size of residues, medium (m) and large (l), used for the contacts is shown. Ten points are given to each stereochemical contact.

foot-printing experiments ${ }^{2}$ that the receptor binds to three regions, 1-3. Region 1 is about three times longer than regions 2 or 3 , which suggests that a large number of GlcR molecules bind to region 1 (Fig. 3a).

The binding score calculated and plotted along the two DNA strands of MMTV-LTR shows that the highest score is given to the four sites, Ia, Ib, Ic, and III on the same DNA strand, which coincides very well with the protected regions 1 and 3, respectively (Fig. 3a). Around region 2 one of the second highest peaks, II, can be seen.

The two types of examination prove that the DNA-recognition rules are specific.

3. Spacing rules for transcription factors of $\mathrm{C} 4$. The recognition helices of the $\mathrm{C} 4$ class are well designed so that they bind selectively to their partner sequences of DNA. 
a EstR

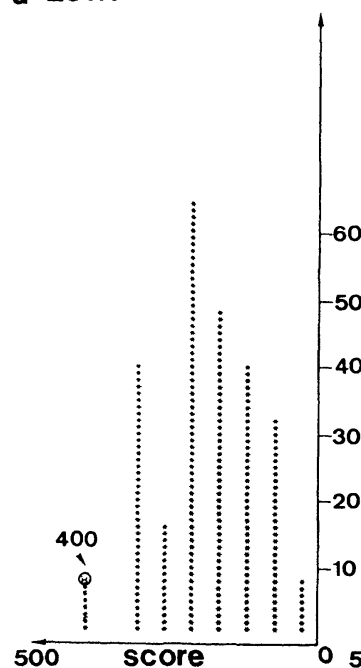

b GluR

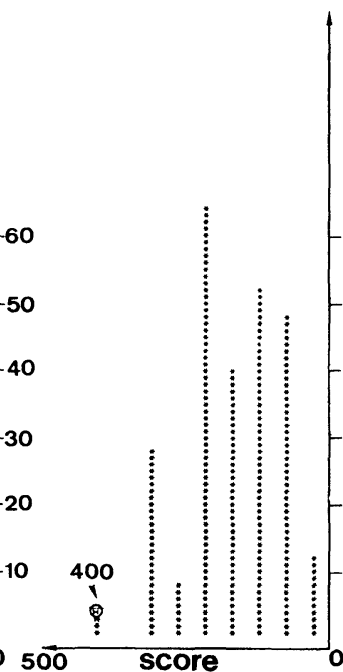

CGATA

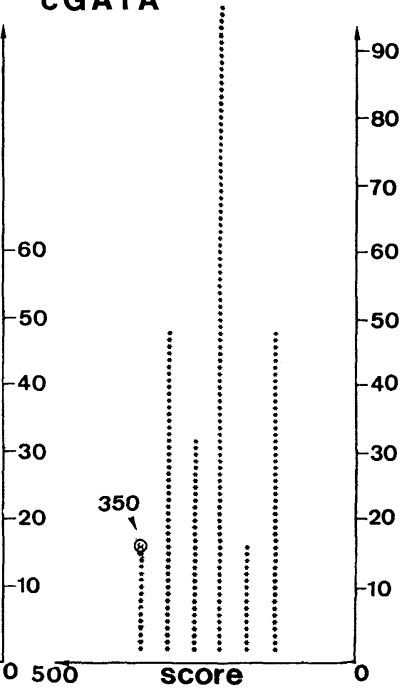

Fig. 2. Specificity of the recognition rules for $\mathrm{C} 4$. The charts show the distribution of the binding score for the 256 combinations of four base pairs matched with the amino acid sequences of oestrogen receptor (a), glucocorticoid receptor (b), and GATA1 (c). The $x$ axis shows the binding score, while the y axis the number of DNA sequences. The scores for the experimentally identified binding sites are marked with arrows.
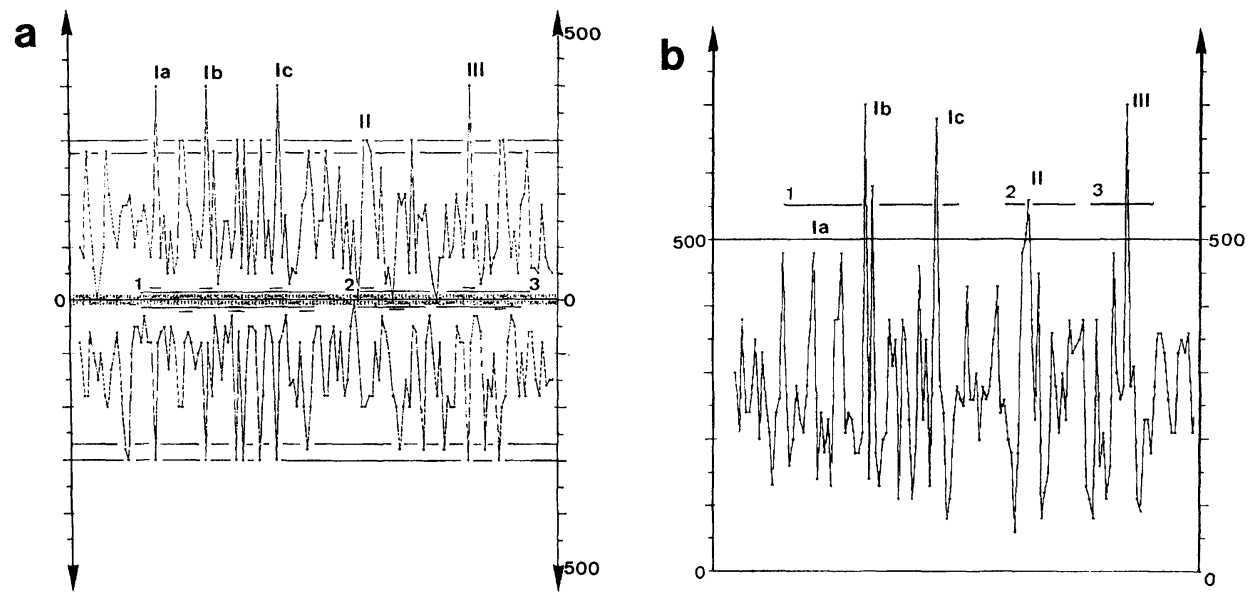

Fig. 3. Prediction of binding sites of glucocorticoid receptor in MMTVLTR. (a) The binding score is calculated for the two DNA strands independently. The score is calculated for every four bases and is plotted. The experimentally identified binding regions, 1, 2, 3, are marked with solid lines. The predicted binding sites, Ia, Ib, Ic, II, and III, on the upper DNA strand are shown with bars. GlcR forms a dimer and the partner monomers bind to the bottom DNA strand. Their binding sites are also shown with bars. (b) The two binding scores to the different DNA strands are added to each other by using the spacing rules (see text). 
However, any recognition helix can bind only to five base pairs or less. The curvature of the major groove of DNA is too great for an $\alpha$-helix to follow and so it can bind only to one side of the DNA. To recognise more than five base pairs, two or more helices must be used in combination. Thus the spacing rules (Suzuki and Gerstein, in preparation, Suzuki et al., in preparation) which describe the separation between the two helices along the DNA and the N-C direction of the two helices relative to each other also become important for discriminating between DNA sequences.

Concerning the $\mathrm{N}-\mathrm{C}$ direction, two different ways are possible for combining two helices, relating the two domains by a two fold symmetry axis like classic helix-turn-helix proteins or repeating them in tandem as is seen with zinc fingers. The $\mathrm{C} 4$ family uses both ways. $^{3)-5)}$

Glucocorticoid receptor ${ }^{6)}$ forms a dimer in which the two monomers are related by two fold symmetry upon binding to DNA and the two binding sites on DNA are five base pairs apart. Indeed the high peaks in Fig. 3a on the upper strand are followed by high peaks in the bottom DNA strand after a spacing of five bases. It is therefore possible to improve the plot by putting the two scores to the different DNA strands together (Fig. 3b)-i.e. by shifting the score to one strand by five bases relative to the other and by adding the resultant scores together. In the new plot (Fig. 3b) site II is given a score higher than that given to Ia.

Retinoid X receptor (RXR) binds to DNA in a "repeating" arrangement. ${ }^{8), 9)}$ Its monomer structure has been determined ${ }^{10)}$ but its structural elements used for dimerisation remain unknown. Two repeating monomers cannot use the same structural element for dimerisation and so different monomers must use different structural elements (Fig. 4b). A monomer of a hormone receptor is composed of two domains, each of which has a loop and an $\alpha$-helix and binds a zinc ion (Fig. 4). For the symmetrical arrangement only

a

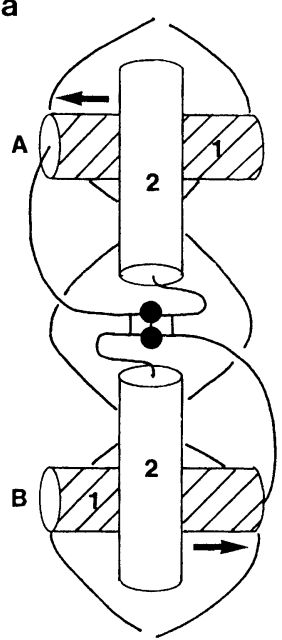

b

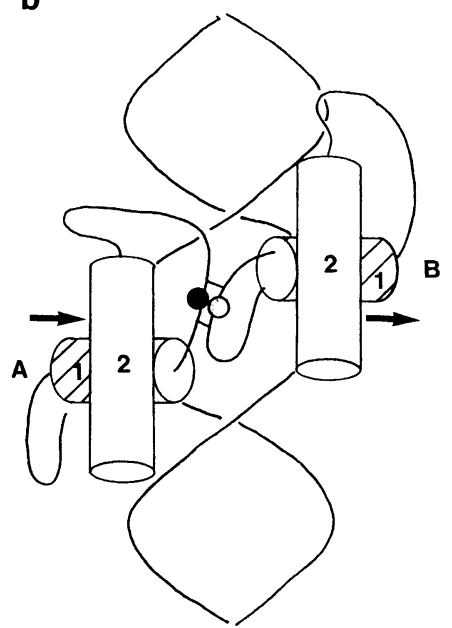

Fig. 4. Symmetrical (a) and repeating (b) arrangements of two hormone receptor molecules. Each of the two monomers (A, B) is further composed of two domains $(1,2)$. Each domain has a loop at the $\mathrm{N}$-terminus and a helix at the C-terminus. The first helix (the recognition helix, hatched) binds to DNA. The arrow shows the N-C direction of the recognition helices. The sites used for dimerisation are marked with circles. 
the second loop is used for dimerisation (Fig. 4a), but for the repeating arrangement, the first loop of one monomer and the second loop of the other monomer might be used for dimerisation (Fig. 4b).

Acknowledgements. We thank Drs J. Finch and C. Chothia for their critical reading of the manuscript.

\section{References}

1) Suzuki, M., and Chothia, L.: Proc. Japan Acad., 70B, 58-61 (1994).

2) Perlmann, T., and Wrange, Ö.: EMBO J., 10, 3073-3079 (1988).

3) Naar, A. M. et al.: Cell, 65, 1267-1279 (1991).

4) Umesono, K. et al.: ibid., 65, 1255-1266 (1991).

5) Schwabe, J. W. R., and Rhodes, D.: Trends Biochem. Sci., 16, 291-296 (1991).

6) Luisi, B. F. et al.: Nature, 352, 497-505 (1991).

7) Schwabe, J. W. R. et al.: Cell, 75, 567-578 (1993).

8) Umesono, K., and Evans, R. M.: ibid., 57, 1139-1146 (1989).

9) Mader, S. et al.: Nature, 338, 271-274 (1989).

10) Lee, M. S. et al.: Science, 260, 1117-1121 (1993). 